\title{
Sejarah matematika: Alternatif strategi pembelajaran matematika
}

\author{
Kamirsyah Wahyu, Sofyan Mahfudy ${ }^{1}$
}

\begin{abstract}
Abstrak: Sejarah merupakan sumber pengetahuan. Sejarah memberikan informasi berharga terkait perkembangan di masa lampau yang mendukung kemajuan di masa sekarang. Dalam hal ini, sejarah matematika juga memberikan pengetahuan bagaimana konsep matematika berkembang. Sejarah matematika menjelaskan, sebagai contoh, bagaimana al-Khwarizmi mengembangkan metode kuadrat sempurna dalam menyelesaikan persamaan kuadrat. Melalui sejarah matematika, kerja keras para matematikawan dalam menemukan dan mengembangkan suatu konsep atau penyelesaian suatu permasalahan bisa menjadi kisah inspiratif. Pengetahuan yang diperoleh melalui sejarah matematika sangat bermanfaat untuk digunakan dalam pembelajaran. Tulisan ini mencoba menjawab kenapa dan bagaimana penerapan sejarah matematika dalam pembelajaran melalui kajian pustaka (library research). Referensi terkait berupa ebook, artikel jurnal online dan proceedings konferensi dianalisis dengan memfokuskan pada dua hal, yaitu: manfaat sejarah matematika dalam membangun sikap positif siswa terhadap matematika; dan cara menerapkan sejarah matematika dalam pembelajaran matematika di Indonesia.
\end{abstract}

Kata kunci : Sejarah matematika; Pembelajaran matematika; Strategi pembelajaran

\begin{abstract}
History is a source of insight. History gives valuable information regarding the development in the past which contributes to the advance nowadays. In this case, the history of mathematics (HoM) also provides knowledge on how mathematics concept developed. The history of mathematics explains, for example, how alKhwarizmi developed one of the methods in solving quadratic equation. In the history of mathematics, how mathematicians worked hard in inventing and developing a concept or a solution upon a mathematics problem can be inspired story. Insight from the history of mathematics can be very useful for learning mathematics. This paper tries to answer why and how the use of history of mathematics in mathematics learning through library research. References consist of e-books, online journal articles and conference proceedings are thoroughly analyzed focusing on two cases, i.e. how the history of
\end{abstract}

\footnotetext{
${ }^{1}$ Institut Agama Islam Negeri (IAIN) Mataram, Mataram, Indonesia, wahyu.iainmataram@gmail.com
} 
mathematics builds positive attitude of students toward mathematics; and how it can be implemented in Indonesia mathematics classroom.

Keywords: History of mathematics; Mathematics learning; Learning strategy

\section{A. Pendahuluan}

Karakteristik pembelajaran matematika yang banyak ditemukan di kelas yaitu fokus pada perhitungan (drill), peran guru lebih dominan (teacher-centered), siswa belum diberikan kesempatan dan didorong untuk menyampaikan pendapat (reasoning), tidak membangun pemahaman konsep, belum berorientasi pemecahan masalah, dan tidak dikaitkan dengan kehidupan sehari-hari. Ketika siswa kelas 5 SD diajarkan perkalian pecahan, sebagian besar guru matematika memulai dengan menjelaskan langsung bagaimana cara mengalikan pecahan yang disertai beberapa contoh sejenis kemudian diakhiri dengan soal latihan. Karakteristik ini senada dengan pendapat Sembiring, Hadi, \& Dolk (2008) yang menyatakan bahwa guru matematika yang menerapkan pembelajaran matematika tradisional yang dicirikan dengan alur openingexample-exercise-closing membuat siswa pasif dan memiliki sedikit kemampuan dalam berpikir dan memberikan alasan secara matematis (mathematical thinking and reasoning). Dengan karakteristik tersebut, pembelajaran matematika hanya sebatas pemindahan pengetahuan (transmission of knowledge) atau belum mencapai pembelajaran sebagai proses membangun pengetahuan (construction of knowledge).

Efek lebih lanjut terkait pembelajaran matematika yang bersifat transmission of knowledge yaitu kurang bermaknanya pembelajaran dan siswa dianggap pintar matematika jika bisa mengerjakan soal sesuai dengan contoh yang dijelaskan. Banyak guru matematika membuat klasifikasi kemampuan matematika siswa di kelas berdasarkan kriteria tersebut. Siswa yang dianggap pintar karena bisa menyelesaikan soal latihan yang lebih menitikberatkan aspek prosedural belum tentu memiliki kemampuan dalam memecahkan masalah matematika yang berkaitan dengan kehidupan sehari-hari (Wahyu, 2015).

Pembelajaran matematika yang kurang bermakna membuat siswa merasakan belajar matematika hanya sekedar sekumpulan aturan yang 
harus dihafal dan dikerjakan. Schoenfeld dalam Riedesel, dkk. (1996) merangkum beberapa pandangan siswa terhadap matematika, yaitu: hanya memiliki satu jawaban benar, tidak perlu memahami kenapa dikerjakan dengan cara tertentu, hanya orang pintar yang menemukan dan membuat matematika, dan masalah matematika sedikit kaitannya dengan kehidupan nyata.

Beberapa pandangan tersebut tentunya melahirkan sikap negatif siswa terhadap pelajaran matematika. Sikap negatif siswa bisa dilihat dari kurangnya minat dan motivasi siswa untuk belajar matematika. Akhirnya, matematika hanyalah momok dalam kelas. Inilah realitas pembelajaran matematika yang tidak bisa dipandang sebelah mata khususnya oleh guru matematika.

Salah satu sebab munculnya sikap negatif siswa terhadap pelajaran matematika adalah cara atau strategi guru menyajikan matematika dalam kelas. Kebanyakan guru matematika mengajarkan matematika dengan tell-do-teaching method (John, 1988 dalam Marks, dkk. 1985), awalnya memberikan penjelasan disertai contoh kemudian memberikan latihan. Papert (dalam Riediesel, dkk. 1996) menyebutkan dengan istilah blankmind theories, "l empty my mind and let the teacher tell me what to do". Pendapat dua ahli tersebut sejalan dengan pembelajaran matematika tradisional yang dikemukan Sembiring, dkk. (2008)

Pembelajaran matematika yang lebih mengaktifkan siswa (studentcentered), menyenangkan dan bermakna merupakan tuntutan mutlak bagi seorang guru matematika. Hal ini sejalan dengan tuntutan kurikulum baik KTSP atau kurikulum 2013 (K13), bahkan dalam K13 semua pelajaran khususnya matematika harus memuat pendidikan karakter. Pembelajaran harus mampu memberikan nilai-nilai positif bagi siswa sebagai modal dalam pembentukan karakter.

Penerapan sejarah matematika dalam pembelajaran merupakan salah satu alat (history as a tool) atau strategi untuk membangun pembelajaran yang bermakna dan sarat dengan nilai. Panasuk \& Horton (2012) mendasari penelitian terkait persepsi guru matematika terhadap penerapan sejarah matematika dengan tiga asumsi kunci yaitu: (1) sejarah matematika memberikan landasan pemahaman yang mendalam tentang evolusi konsep matematika; (2) memahami kenapa dan bagaimana konsep matematika dikembangkan selama bertahun-tahun dengan kerja 
keras; (3) belajar sejarah matematika bisa meningkatkan minat dan mengembangkan sikap positif siswa terhadap matematika. Poin ke (3) terbukti dengan penelitian Lawrence (2008).

Dalam tulisan ini, penulis mencoba menjawab pertanyaan kenapa dan bagaimana penerapan sejarah matematika dalam pembelajaran. Pembahasan difokuskan pada dua hal, yaitu: manfaat sejarah matematika dalam membangun sikap positif siswa terhadap matematika; dan merumuskan cara menerapkan sejarah matematika dalam pembelajaran matematika yang disesuaikan dengan konteks Indonesia. Pembahasan dalam makalah ini berdasarkan kajian teoritis dan beberapa hasil studi empiris.

Ada beberapa hal yang membuat penulis tertarik untuk menulis topik ini, yaitu: (1) sejarah merupakan sumber pembelajaran. Dalam hal ini, belum banyak guru atau mungkin belum ada yang memanfaatkan sejarah matematika dalam pembelajaran. Penulis mencoba mencari kata kunci "penerapan sejarah matematika dalam pembelajaran" di Google (10 Agustus 2016), hanya ada satu judul relevan yang muncul yaitu sebuah artikel oleh Sumardyono (2012) di website P4TK Matematika dan beberapa website lain yang mengutip artikel tersebut. Penulis juga mencari dengan kata kunci "sejarah matematika dalam pembelajaran matematika" di portal Garuda (id.portalgaruda.org) yang memuat banyak judul artikel jurnal di Indonesia. Hasilnya tidak ditemukan judul artikel yang sesuai dengan kata kunci pencarian. Tulisan ini diharapkan menjadi referensi tambahan dan pencerahan bagi pihak terkait khususnya guru matematika terkait manfaat sejarah matematika dalam pembelajaran. (2) penerapan sejarah matematika dalam pembelajaran telah menjadi salah satu topik penelitian penting dan menarik. Dalam CERME 6 - CERME 9, sejarah matematika menjadi salah satu working group (WG) yang memuat hasil penelitian dan diskusi terkait topik tersebut.

\section{B. Metode Penulisan}

Penulisan artikel ini menggunakan metode studi pustaka (library research). Penulis mengumpulkan referensi terkait sejarah matematika dalam pembelajaran berupa ebook, artikel jurnal online, dan proceedings konferensi. Ketiga jenis referensi ini memuat hasil penelitian dan kajian 
pustaka terkait topik. Referensi tersebut dibaca secara seksama untuk memperoleh penjelasan yang rinci terkait kenapa dan bagaimana menerapkan sejarah matematika. Pengetahuan yang diperoleh melalui referensi dianalisis dan disesuaikan dengan konteks pembelajaran matematika di Indonesia khususnya tuntutan kurikulum yang diterapkan. Hasil analisis menghasilkan penguatan terkait pentingnya penerapan sejarah matematika dalam pembelajaran berdasarkan kajian pustaka dan rumusan cara menerapkannya dalam pembelajaran yang disesuaikan dengan konteks pembelajaran matematika.

\section{Pembahasan}

Wacana integrasi (integrating atau incorporating) sejarah matematika dalam pembelajaran sudah lama bergulir namun publikasi hasil penelitian baru mulai massif sejak tahun 2000. Salah satunya adalah publikasi melalui ICME-9 (International Congress on Mathematics Education). Di tahun yang sama, diterbitkan sebuah buku penting terkait penerapan sejarah matematika oleh ICMI (International Commission on Mathematics Instruction) yang berjudul History in Mathematics Education: An ICMI Study (Fauvel \& Maanen, 2000). Buku ini salah satunya membahas alasan kenapa ('the whys') dan bagaimana ('the hows') penerapan sejarah matematika dalam pembelajaran. Selanjutnya, topik ini menjadi salah satu work group (WG) di Congress of the European Society for Research in Mathematics Education (CERME) tahun 2009.

Secara umum, sejarah matematika dapat diartikan sebagai sekumpulan kejadian yang terjadi pada masa lampau dan berhubungan dengan perkembangan matematika (Sumardyono, 2003). Oleh sebab itu, sejarah matematika dapat memberikan pemahaman tentang konsep matematika dan kenapa konsep tersebut ada. Secara khusus sebagai sebuah bidang kajian, sejarah matematika merupakan sebuah penyelidikan terkait asal-usul penemuan dalam matematika yang meliputi metode dan notasi matematika pada masa lampau (Wikipedia). Matematika dan sejarahnya tidak bisa dipisahkan satu sama lain. Keterikatan matematika dan sejarahnya ditegaskan oleh Galishier (18481928) dalam (Panasuk \& Horton, 2012) yaitu "I am sure that no subject 
loses more than mathematics by any attempt to dissociate it from its history."

Menurut Barbin (2000), ada dua alasan penting terkait penerapan sejarah matematika dalam pembelajaran yaitu sejarah matematika memberikan kesempatan untuk membangun persepsi terkait apakah sebenarnya matematika dan memungkinkan kita memiliki pemahaman yang lebih baik terkait konsep dan teori matematika. Dalam setiap dua hal tersebut, ada urutan membangun pemahaman yaitu pada awalnya sejarah matematika bisa mengubah persepsi dan pemahaman guru tentang matematika, kemudian sejarah matematika akan mempengaruhi bagaimana cara guru mengajarkan matematika, dan pada akhirnya akan mempengaruhi cara siswa menerima dan memahami matematika. Efektivitas penerapan sejarah matematika bisa dinilai melalui alur proses tersebut.

Kjeldsen (2011) menganalisis laporan guru-guru yang mengikuti inservice training (sejenis diklat guru) pada tahun 2005. Guru-guru tersebut melaksanakan proyek bernama Egyptian Mathematics di kelas 10, di Denmark. Hasil analisis menunjukkan bahwa sejarah matematika dapat menciptakan lingkungan belajar yang kaya, membangun kesadaran sejarah siswa, mengembangkan strategi belajar, dan memperluas keterampilan pemecahan masalah walaupun para siswa mengerjakan matematika yang bukan bagian dari kurikulum inti.

Pada tahun 2007, Goodwin (2010) melakukan sebuah penelitian di California Public School untuk mengetahui urgensi guru mengetahui sejarah matematika. Hasilnya menunjukan bahwa terdapat hubungan signifikan apa yang diketahui oleh guru tentang sejarah matematika dengan kepercayaan terhadap matematika. Guru dengan nilai sejarah matematika yang lebih rendah kurang mempercayai bahwa matematika merupakan ilmu atau disiplin untuk semua orang dan adanya perbedaan budaya dalam matematika. Guru dengan skor rendah mempercayai bahwa matematika merupakan sekumpulan fakta-fakta terpisah, aturan dan keterampilan, serta segala sesuatu yang penting tentang matematika telah diketahui. Goodwin (2010) menyimpulkan bahwa dengan mengetahui sejarah matematika sangat bernilai secara pedagogik karena memberikan konteks matematika. Sejarah matematika menunjukan kepada guru dan siswa karakteristik matematika. 
Lawrence (2008) menemukan hasil yang signifikan dalam dua penelitiannya. Penelitian pertama dilakukan di Edmund's Catholic School tahun akademik 2004/2005 dengan beberapa hasil penting yaitu: penerapan sejarah matematika dalam pembelajaran meningkatkan motivasi siswa, siswa mulai melakukan investigasi secara mandiri, keterampilan komunikasi siswa mengalami perbaikan, dan kohesi kelas mempengaruhi perluasan dimana siswa merasa antusias dalam berpartisipasi. Penelitian kedua dilaksanakan di sekolah dasar dan menengah bagian tenggara Inggris, September 2006-September 2008. Penelitian tersebut bertujuan untuk memperkenalkan sejarah matematika dalam kurikulum melalui praktek kolaborasi pengajaran. Hasil penelitian tersebut adalah penerapan sejarah matematika bisa meningkatkan motivasi dan menciptakan landasan konseptual yang akan menjadi dasar bagi guru dalam lingkungan pengembangan profesi yang berkelanjutan.

Clark (2011) melakukan penelitian bersama beberapa guru terkait penerapa sejarah matematika dalam tiga kategori, yaitu: sejarah sebagai anekdot (history as anecdote); sejarah sebagai biografi (history as biography); dan sejarah sebagai sumber masalah yang menarik (history as interesting problems). Tiga kategori penerapan sejarah matematika tersebut diadaptasi dari Siu (1997). Hasilnya penilaian tergolong signifikan karena dua alasan, yaitu: perspektif sejarah sebagai sumber masalah yang menarik melibatkan siswa dalam konten matematika; dan hal ini memungkinkan siswa melakukan investigasi cara penyelesaian alternatif.

\section{Kenapa dan Bagaimana?}

Hasil studi (Kjeldsen, 2011; Goodwin, 2010; Lawrence, 2008; Clark, 2011) yang dijelaskan di atas memberikan jawaban mendasar kenapa menerapkan sejarah matematika dalam pembelajaran. Pembahasan lebih rinci untuk menjawab pertanyaan kenapa dan bagaimana penerapan sejarah matematika dalam pembelajaran, penulis menganalisis tulisan Tzanakis \& Arcavi (2000), Jankvist (2009a, 2009b) dan beberapa referensi terkait.

'The whys'

Fauvel (2000) menyebutkan tiga efek positif penerapan sejarah matematika dalam pembelajaran yaitu pemahaman, antusias dan 
keterampilan. Sejarah matematika akan menunjukan bahwa matematika merupakan aktivitas manusia. Disamping itu, sejarah matematika memiliki tiga nilai yaitu sebagai materi pembelajaran, konteks materi pembelajaran dan sumber strategi belajar.

Bruckler (2001) memberikan beberapa rincian peran sejarah matematika untuk guru, yaitu: (a) sebagai sumber contoh yang menarik dan menyenangkan dalam pembelajaran; (b) dengan menggunakan versi sejarah, konsep matematika akan lebih mudah dipahami dan menarik; (c) menambah pengetahuan untuk topik yang sudah diketahui; dan (d) membuat siswa memahami bahwa matematika bukan pelajaran tanpa makna.

Jankvist (2009a) memperkenalkan dua tujuan (purposes) dimana sejarah matematika (HoM, history of mathematics) bisa bermanfaat dan relevan dengan pembelajaran matematika (ME, mathematics education) yaitu sejarah sebagai alat (history-as-a-tool) dan sejarah sebagai tujuan (history-as-a-goal). Sejarah sebagai alat berkaitan dengan bagaimana siswa belajar matematika. Dalam hal ini, sejarah matematika bisa menjadi faktor motivasi bagi siswa untuk mempertahankan minat dan kesenangan mempelajari matematika. Di samping itu, sejarah matematika juga menunjukan kepada siswa wajah matematika yang 'lebih manusiawi', dan, yang paling utama, sejarah sebagai alat untuk mendukung pembelajaran matematika. Sejarah matematika sebagai tujuan tidak berarti menjadikan sejarah matematika sebagai topik yang berdiri sendiri tetapi fokusnya terletak pada aspek perkembangan matematika sebagai disiplin ilmu. Dalam hal ini, sejarah matematika dikatakan sebagai tujuan untuk menunjukan siswa bahwa matematika itu ada dan berkembang dalam ruang dan waktu.

Tzanakis \& Arcavi (2000) merangkum 'the whys' penerapan sejarah matematika dalam pembelajaran, yaitu:

1. Pembelajaran matematika

a. Perkembangan sejarah: untuk menunjukan konsep, metode, teori dan lain-lain.

b. Sejarah sebagai sumber: untuk memotivasi, meningkatkan minat, mengikutsertakan siswa dengan menghubungkan pengetahuan sekarang dan proses belajar dengan pengetahuan dan masalah pada masa lampau. 
c. Matematika sebagai jembatan antara matematika dan displin lain: darimana dan bagaimana bagian-bagian matematika muncul? Untuk menggabungkan aspek, pelajaran dan metode baru.

d. Nilai pendidikan sejarah yang lebih umum: untuk membangun kemajuan personal dan keahlian, tidak selamanya berkaitan dengan matematika.

2. Karakteristik matematika dan aktivitas matematika

a. Konten: untuk memperoleh pengetahuan tentang konsep, konjektur dan pembuktian, dengan melihat sudut pandang yang berbeda.

b. Bentuk: untuk membandingkan yang lama dan modern; untuk memotivasi pembelajaran dengan menekankan pada aspek kejelasan, kesadaran dan kelengkapan logis.

3. Latar belakang didaktis (pengajaran) guru

a. Identifikasi motivasi: untuk melihat rasionalitas dibalik pengenalan pengetahuan dan perkembangan baru.

b. Kesadaran akan kesulitan dan halangan: untuk menyadari tentang kemungkinan adanya kesulitan pengajaran dan analogi antara kelas dan evolusi sejarah.

c. Menjadi bagian dan/atau menyadari adanya proses kreatif dalam mengerjakan matematika (doing mathematics): menyelesaikan masalah dalam konteks sejarah; memperkaya khasanah matematika; menghargai karakteristik matematika.

d. Memperkaya sisi pengajaran (didaktik): untuk meningkatkan kemampuan menjelaskan, pendekatan, memahami bagianbagian kecil matematika.

e. Merubah dan memahami pendekatan yang berbeda dan/atau tidak konvensional terhadap matematika: untuk mempelajari bagaimana bagian matematika yang sudah dikenal dalam konteks yang berbeda (lama); dalam hal ini untuk meningkatkan sensitivitas dan toleransi terhadap matematika yang salah.

4. Predisposisi afektif terhadap matematika

a. Memahami matematika sebagai capaian manusia 
b. Melanjutkan eksistensi ide-ide, mengusahakan inkuiri, memberikan pertanyaan.

c. Tidak dilemahkan oleh kegagalan, kesalahan, ketidaktentuan, dan kesalahpahaman.

5. Apresiasi terhadap matematika sebagai sebuah capaian budaya

a. Matematika tidak hanya ada oleh alasan atau kebutuhan praktis tetapi tetapi oleh kepentingan matematika itu sendiri, termotivasi oleh kriteria keindahan, keingintahuan intelektual, tantangan dan kesenangan, tujuan rekreasional dan lainnya.

b. Memberikan contoh perkembangan internal matematika yang tidak hanya dipengaruhi oleh faktor praktis tetapi juga dipengaruhi bahkan ditentukan oleh faktor sosial dan budaya.

c. Matematika bukan hanya produk dari kebudayaan tertentu (misalnya Barat) tetapi juga lahir dari kebudayaan yang beragam.

'The hows'

Jankvist (2009b) mengusulkan tiga pendekatan untuk menerapkan sejarah matematika yaitu:

1. Pendekatan iluminasi (illumination approach): pembelajaran matematika, dalam kelas atau penggunaan buku teks, dilengkapi dengan informasi sejarah yang bervariasi dalam penekanan dan banyaknya yang diajarkan.

2. Pendekatan modul (modules approaches): beberapa unit pembelajaran dikhususkan untuk sejarah, dan biasanya berdasarkan pada studi rinci tentang hal-hal khusus.

3. Pendekatan berdasarkan sejarah (history-based approaches): Secara langsung diinspirasi oleh, atau berdasarkan pada HoM. Tidak mempelajari HoM secara langsung, tetapi secara tidak langsung.

Furingheti (1997) dalam (Sumardyono, 2003) mengusulkan taksonomi penerapan sejarah matematika, yaitu: menginformasikan sejarah matematika untuk merubah persepsi siswa terhadap matematika; digunakan sebagai sumber latihan atau masalah dan aktivitas tambahan; dan sebagai pendekatan alternatif untuk membuat siswa paham konsep 
matematika. Sementara itu, Siu (1997) mengenalkan empat kategori atau tingkatan yang disingkat $A B C D$ perapan sejarah untuk mengajar mahasiswa, yaitu: anekdot (Anecdote); memberikan gambaran yang luas pada awal atau akhir pembelajaran menggunakan sejarah matematika (Broad outline); konten sejarah (Content); dan pengembangan ide matematika (Development of mathematical ideas).

Secara umum, Tzanakis dan Arcavi (2000) merangkum tiga kategori penerapan sejarah matematika, yaitu:

1. Mempelajari sejarah (learning history), dengan menyajikan informasi sejarah secara langsung.

Informasi sejarah secara langsung terdiri dari dua jenis, yaitu: informasi faktual seperti nama-nama matematikawan, biografi, permasalahan dan pertanyaan yang terkenal, dan lainnya; dan buku sejarah matematika. Penggunaan informasi sejarah secara langsung lebih fokus pada aspek sejarah daripada pembelajaran matematika.

2. Mempelajari topik matematika (learning mathematical topics), dengan pendekatan sejarah.

Kategori kedua ini disebut sebagai pendekatan genetik untuk pembelajaran matematika karena tidak terlalu deduktif dan fokus pada aspek sejarah. Fokus pendekatan ini adalah setidaknya bagaimana menggunakan teori, metode dan konsep, dan lebihnya kenapa materi/sumber sejarah yang digunakan memberikan jawaban terhadap pertanyaan dan masalah matematika. Dalam hal ini, pendekatan sejarah menawarkan kemungkinan yang menarik untuk pemahaman matematika yang dalam dan umum.

3. Membangun kesadaran yang lebih dalam (developing deeper awareness) terkait matematika itu sendiri dan konteks sosial serta budaya dimana matematika dikerjakan.

Ada dua kesadaran yang dibangun melalui pendekatan ini yaitu kesadaran instrinsik dan ekstrinsik terkait karakteristik aktivitas matematika. Kesadaran instrinsik berkaitan dengan perkembangan matematika baik dalam bentuk isi maupun bentuk seperti notasi, istilah, metode perhitungan, pembuktian dan lainnya. Kesadaran ekstrinsik berkaitan dengan matematika 
sebagai bagian yang tidak terpisahkan dari disiplin ilmu yang lain seperti filsafat, seni dan sains serta sebagai bagian penting dari kebudayaan dan peradaban.

Tzanakis dan Arcavi (2000) lebih lanjut memberikan beberapa contoh cara penerapan sejarah matematika berdasarkan hasil survei di beberapa negara, yaitu:

1. Historical snippets (Cuplikan sejarah): Informasi sejarah matematika berupa kisah matematikawan dimuat dalam buku teks matematika.

2. Historical texts: Teks sejarah digunakan untuk mempelajari dan mengembangan konsep matematika seperti Angle Trisection: A Classical

Problem

(https://en.wikipedia.org/wiki/Angle trisection)

3. Primary sources: Sumber sejarah matematika berupa teks dan gambar asli digunakan dalam pembelajaran.

4. Worksheets (Lembar Kerja, LK): LK berisi latihan atau aktivitas pembelajaran yang berkaitan dengan sejarah.

5. Historical packages (Paket sejarah): Yang dimaksud paket sejarah yaitu kumpulan materi sejarah yang hanya fokus pada beberapa topik tertentu, misalnya geometri.

6. Historical problems: Masalah sejarah digunakan sebagai sumber belajar seperti pembuktian teorema Phytagoras yang bervariasi di berbagai kebudayaan.

7. Mechanical instruments: Intrumen mekanik dalam pembelajaran matematika digunakan untuk memberikan ilustrasi terkait konsep matematika dan pembuktian. Misalnya, menyelesaikan permasalahan geometri Yunani kuno.

8. Experiential mathematical activities: Contoh kegiatan matematika yaitu menggunakan metode yang pernah digunakan di masa lampau untuk menyelesaikan suatu permasalahan, permainan, dan drama.

9. Films and other visual means: Film yang berkaitan dengan sejarah matematika bisa digunakan sebagai sumber belajar seperti The hill on the dark side of the moon yang menceritakan kisah Sofia Kovalevskaya. 
10. Outdoor experiences: Kegiatan di luar kelas seperti berkunjung ke museum yang memiliki produk matematika di masa lampau

11. World Wide Web: Sumber online bisa digunakan sebagai sumber dan alat komunikasi. Banyak website yang menyediakan sumber sejarah bagi pembelajaran seperti http://www.storyofmathematics.com/

Menurut penulis, penerapan sejarah matematika oleh Jankvist (2009b), Furingheti (1997), dan Siu (1997) sudah termasuk dalam tiga kategori yang dikemukan oleh Tzanakis dan Arcavi (2000). Tabel 1 berikut memberikan penjelasan terkait tiga kategori tersebut.

Tabel 1. Kategori Penerapan Sejarah Matematika

\begin{tabular}{|l|l|l|l|}
\hline $\begin{array}{c}\text { Tzanakis dan Arcavi } \\
\text { (2000) }\end{array}$ & \multicolumn{1}{|c|}{ Siu (1997) } & \multicolumn{1}{c|}{$\begin{array}{c}\text { Furingheti } \\
\text { (1997) }\end{array}$} & Jankvist (2009b) \\
\hline $\begin{array}{l}\text { 1. Mempelajari } \\
\text { sejarah }\end{array}$ & Anekdot (A) & $\begin{array}{l}\text { Informasi sejarah } \\
\text { untuk merubah } \\
\text { persepsi siswa }\end{array}$ & $\begin{array}{l}\text { Pendekatan } \\
\text { iluminasi; } \\
\text { pendekatan } \\
\text { modul }\end{array}$ \\
\hline $\begin{array}{l}\text { 2. Mempelajari topik } \\
\text { matematika } \\
\text { dengan } \\
\text { pendekatan } \\
\text { sejarah }\end{array}$ & $\begin{array}{l}\text { Broad Outline } \\
\text { (B), Content (C) } \\
\text { dan } \\
\text { Development of } \\
\text { Mathematical } \\
\text { Ideas (D) }\end{array}$ & $\begin{array}{l}\text { Sumber } \\
\text { latihan/masalah } \\
\text { dan antivitas } \\
\text { tamanan; } \\
\text { sejarah sebagai } \\
\text { pendekatan } \\
\text { alternatif }\end{array}$ & $\begin{array}{l}\text { Pendekatan } \\
\text { berdasarkan } \\
\text { sejarah }\end{array}$ \\
\hline $\begin{array}{l}\text { 3. Membangun } \\
\text { kesadaran } \\
\text { matematika }\end{array}$ & Anekdot (A) & $\begin{array}{l}\text { Informasi sejarah } \\
\text { untuk merubah } \\
\text { persepsi siswa }\end{array}$ & $\begin{array}{l}\text { Pendekatan } \\
\text { modul }\end{array}$ \\
\hline
\end{tabular}

Untuk menerapkan sejarah matematika dalam pembelajaran, tentunya dibutuhkan sumber materi sejarah. Menurut Tzanakis dan Arcavi (2000), sumber materi sejarah dikelompokan menjadi tiga, yaitu: sumber primer (primary source material); sumber sekunder (secondary source material); dan sumber didaktik (didactical source material). Sumber primer merupakan dokumen asli sejarah perkembangan matematika. Sumber sekunder berupa buku teks yang memuat narasi sejarah, intepretasi dan rekonstruksi. Sumber didaktik merupakan hasil gabungan 
sumber primer dan sekunder yang disesuaikan dengan kebutuhan pembelajaran. Dari ketiga sumber tersebut, sumber didaktik masih kurang. Oleh sebab itu, guru matematika didorong untuk mengembangkan materi sendiri yang bisa mudah digunakan dalam pembelajaran.

Jankvist (2009b), Furingheti (1997), Siu (1997) serta Tzanakis dan Arcavi (2000) sudah memberikan penjelasan cara menerapkan sejarah matematika dalam pembelajaran. Dari berbagai cara tersebut, manakah yang cocok untuk diterapkan dalam konteks pembelajaran matematika di Indonesia disesuaikan dengan tuntutan kurikulum? Penulis mencoba menjawab pertanyaan ini dengan menganalisis berbagai cara penerapan tersebut.

Ada dua hal penting yang harus diperhatikan sebelum menerapkan sejarah matematika, yaitu: apakah penerapan sejarah matematika bisa mengubah persepsi siswa terhadap matematika?; dan apakah penerapan sejarah matematika di kelas bisa membangun dan mengembangkan konsep matematika siswa? Dua pertanyaan ini berkaitan dengan aspek afektif dan kognitif dalam pembelajaran matematika yang juga tuntutan kurikulum baik KTSP maupun K13. Berdasarkan dua hal tersebut, penulis merumuskan alur penerapan sejarah matematika dalam pembelajaran di sekolah dasar sampai perguruan tinggi seperti pada bagan 1.

Menurut penulis, pendekatan berdasarkan sejarah (history-based approach) lebih menjanjikan untuk diterapkan dalam pembelajaran matematika di Indonesia dengan beberapa alasan, yaitu: (a) Tidak fokus pada aspek sejarah sehingga waktu pembelajaran lebih banyak digunakan untuk membangun pemahaman konsep matematika; (b) Konten sejarah berupa kombinasi cuplikan sejarah, konteks pembelajaran dan latihan disesuaikan dengan topik matematika yang akan dipelajari di kelas. Jadi, konten sejarah diambil secara proprosional untuk keperluan pengajaran yang disesuaikan dengan ketersediaan waktu; dan (c) seperti yang dijelaskan Tzanakis dan Arcavi (2000) bahwa fokus penggunaan sejarah matematika adalah bagaimana menggunakan materi/sumber sejarah (teori, metode dan konsep) untuk memberikan jawaban terhadap pertanyaan dan masalah matematika. 


\section{Pendekatan berdasarkan sejarah (history- based approach)}

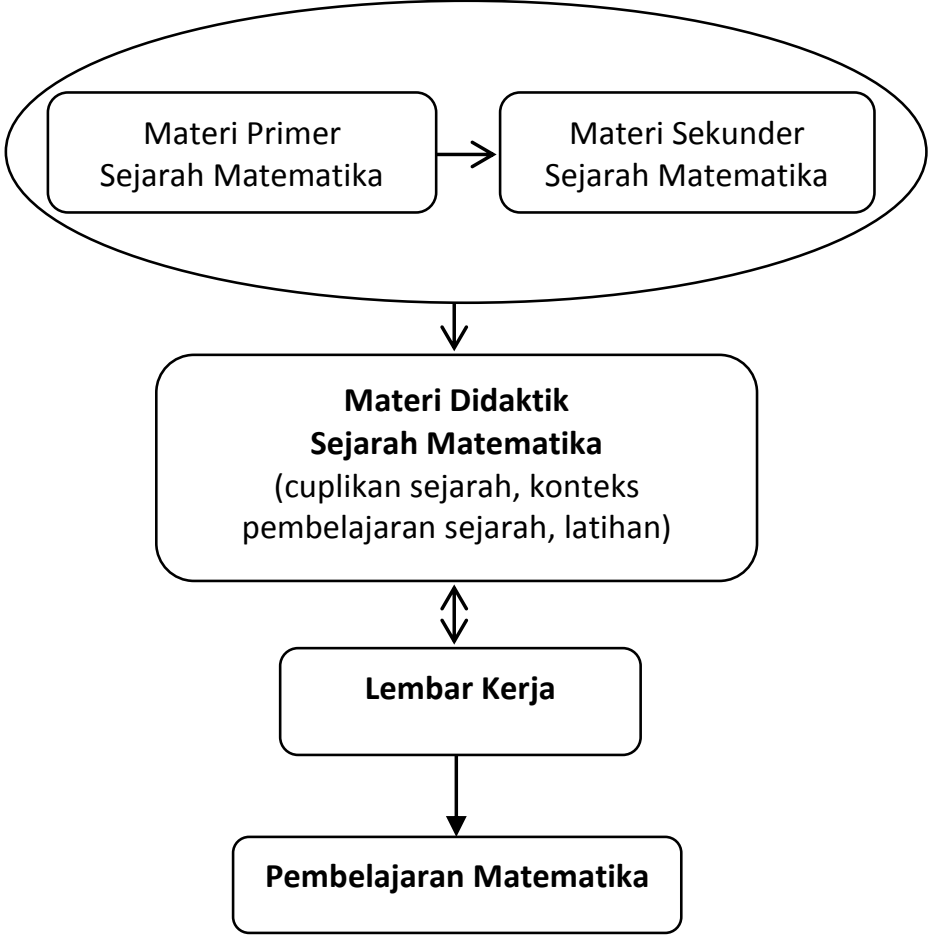

Bagan 1. Alur Penerapan Sejarah Matematika dalam Pembelajaran

Guru matematika mengembangkan materi didaktik sejarah matematika yang diolah dari sumber primer dan/atau sumber sekunder. Materi didaktik ini berupa cuplikan sejarah/anekdot (historical snippets/anecdote), konteks pembelajaran sejarah untuk topik atau konsep yang akan diajarkan (historybased learning context), dan latihan. Ketiga materi didaktik ini disusun dalam bentuk lembar kerja (LK) untuk kelompok atau individu. Satu lembar kerja tidak harus berisi ketiga materi didaktik tersebut karena keterbatasan sumber sejarah yang mencakup ketiga hal tersebut secara bersamaan untuk suatu topik matematika. Yang sangat penting ada dalam LK adalah konteks pembelajaran berdasarkan konten sejarah untuk membangun dan mengembangkan ide atau konsep matematika siswa.

Pemilihan LK sebagai alat untuk menerapkan sejarah matematika dalam pembelajaran didasari oleh beberapa alasan, yaitu: (a) LK lebih mudah digunakan di kelas karena siswa sudah terbiasa menggunakan LK 
dibandingkan dengan modul atau buku yang khusus memuat konten sejarah; (b) guru matematika bisa menyusun LK berbasis sejarah yang disesuaikan dengan ketersediaan sumber sejarah dan kompetensi dasar yang ingin dicapai; (c) cakupan LK (cuplikan sejarah, konteks pembelajaran, dan/atau latihan) tidak terlalu luas jika dibandingkan dengan paket sejarah (historical package) atau modul sehingga tidak membutuhkan waktu yang lama; dan (d) LK yang berisis konteks pembelajaran terkait topik tertentu bisa terus diujicoba dan diperbaiki untuk meningkatkan efektivitas pembelajaran matematika.

Untuk melengkapi penjelasan alur penerapan sejarah matematika dalam pembelajaran, penulis memberikan contoh konten LK yang digunakan untuk mempelajari persamaan kuadrat. Materi didaktik yang diambil yaitu karya al-Khwarizmi dalam matematika (cuplikan sejarah), metode yang dikembangkan oleh al-Khwarizmi untuk menyelesaikan persamaan kuadrat (konteks pembelajaran sejarah), dan latihan yang diambil dari sejarah matematika.

\section{Cuplikan Sejarah}

Pada bagian awal LK, disajikan beberapa informasi penting terkait hasil karya al-Khwarizmi dalam matematika yang bisa mempengaruhi aspek afektif siswa. Beberapa cuplikan sejarah terkait al-Khwarizmi, yaitu:

a. Al-Khwarizmi dan Banu Musa adalah ilmuwan yang bekerja dan belajar di akademi House of Wisdom din Baghdad. Tugas mereka adalah menerjemahkan manuskrip ilmiah Yunani, mempelajarinya, dan menulis tentang aljabar, geometri dan astronomi.

b. Al-Khwarizmi menulis buku berjudul Hisab al-jabr w'al-muqabala (English: The Compendious Book on Calculation by Completion and Balancing; Latin: Liber Algebræ et Almucabola). Judul tersebut pertama kali mengenalkan istilah aljabar dan berisi cara penyelesaian akar positif polinomial sampai derajad 2. Buku ini disebut sebagai fondasi aljabar modern. Al-Khwarizmi mengembangkan cara menyelesaikan persamaan kuadrat yang sekarang kita kenal dengan melengkapi kuadrat sempurna.

c. Buku kedua al-Khwarizmi berjudul Algoritmi de numero Indorum (Latin) atau Al-Khwarizmi on the Hindu Art of Reckoning (English) 
tentang sistem angka Hindu-Arab. Buku ini mengenalkan penggunaan angka 0 dalam nilai tempat dan istilah algoritma.

\section{Konteks Pembelajaran}

Dalam buku Hisab al-jabr w'al-muqabala, al-Khwarizmi mengembangkan cara menyelesaikan persamaan kuadrat. Persamaan kuadrat terdiri dari satuan (units), akar (roots) dan kuadrat (squares). Al-Khwarizmi sama sekali tidak menggunakan simbol dalam bukunya sehingga perlu ditulis dalam notasi yang sudah dikenal sekarang. Satuan merupakan sebuah angka, akar adalah $x$ dan kuadrat adalah $x^{2}$. Untuk menyelesaikan $x^{2}+10 x=39$, al-Khwarizmi menulis sebagai berikut (O'Connor \& Robertson, 1999).

... a square and 10 roots are equal to 39 units. The question therefore in this type of equation is about as follows: what is the square which combined with ten of its roots will give a sum total of 39? The manner of solving this type of equation is to take one-half of the roots just mentioned. Now the roots in the problem before us are 10. Therefore take 5, which multiplied by itself gives 25 , an amount which you add to 39 giving 64. Having taken then the square root of this which is 8, subtract from it half the roots, 5 leaving 3. The number three therefore represents one root of this square, which itself, of course is 9. Nine therefore gives the square.

Deskripsi penyelesaian persamaan kuadrat di atas bisa dijadikan sebagai konteks pembelajaran. Siswa diberikan kesempatan untuk mendiskusikan deskripsi penyelesaian tersebut (diterjemahkan dahulu) dalam kelompok atau individu. Siswa diharapkan mampu menerjemahkannya dalam bentuk aljabar atau geometri seperti pada gambar berikut.

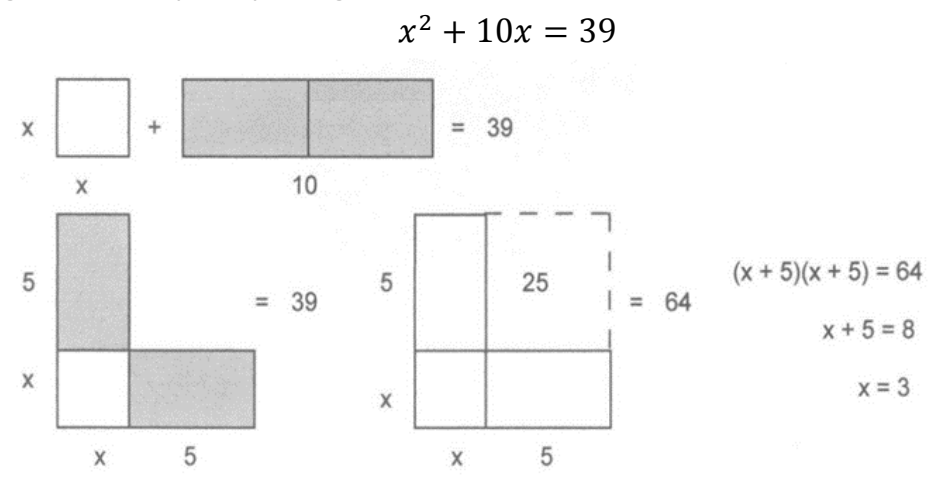

(Hughes, 2011)

Gambar 1. Alternatif penyelesaian persamaan kuadrat metode alKhwarizmi 


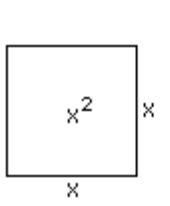

(1)

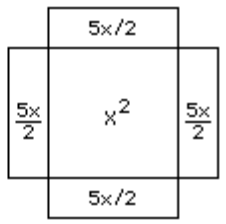

(2)

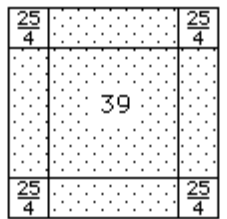

(3)

(O'Connor \& Robertson, 1999).

Gambar 2. Alternatif penyelesaian persamaan kuadrat metode alKhwarizmi

\section{Latihan}

al-Khwarizmi menulis sebuah masalah persamaan seperti berikut (https://en.wikipedia.org/wiki/Muhammad ibn Musa al-Khwarizmi).

... If some one say: "You divide ten into two parts: multiply the one by itself; it will be equal to the other taken eighty-one times. "Computation: You say, ten less thing, multiplied by itself, is a hundred plus a square less twenty things, and this is equal to eighty-one things. Separate the twenty things from a hundred and a square, and add them to eighty-one. It will then be a hundred plus a square, which is equal to a hundred and one roots. Halve the roots; the moiety is fifty and a half. Multiply this by itself, it is two thousand five hundred and fifty and a quarter. Subtract from this one hundred; the remainder is two thousand four hundred and fifty and a quarter. Extract the root from this; it is forty-nine and a half. Subtract this from the moiety of the roots, which is fifty and a half. There remains one, and this is one of the two parts

Permasalahan di atas bisa dijadikan sebagai latihan (diterjemah dahulu). Siswa diminta membuat model persamaan kuadrat dan menyelesaikan dengan metode al-Khwarizmi seperti pada konteks pembelajaran. Jika siswa kemungkinan besar tidak bisa membuat model 
matematika, guru bisa langsung menuliskan persamaan kuadrat sebagai berikut.

$$
\begin{aligned}
& x=\text { the 'thing' atau 'root' } \\
& (10-x)^{2}=81 x \\
& x^{2}-20 x+100=81 x \\
& x^{2}+100=101 x
\end{aligned}
$$

Penerapan sejarah matematika setidaknya bisa memberikan warna baru dalam pembelajaran matematika. Namun, tidak semua guru dapat menerapkannya dalam pembelajaran. Berdasarkan hasil penelitian Panasuk \& Horton (2012), yang mengidentifikasi faktor-faktor pendukung dan yang tidak mendukung penerapan sejarah matematika oleh guru-guru di beberapa negara bagian USA yang melibatkan 367 guru melalui survei online, diperoleh informasi bahwa faktor-faktor yang tidak mendukung yaitu: persepsi guru tentang sejarah matematika, pengetahuan guru tentang sejarah matematika, keterbatasan alokasi waktu dalam kurikulum, ketersediaan bahan, dan senang atau tidaknya mengajarkan sejarah matematika.

Clark (2011) menambahkan bahwa menerapkan sejarah matematika dalam pembelajaran memiliki masalah karena beberapa alasan yaitu mendapatkan pengetahuan tentang perkembangan sejarah memerlukan bimbingan (contohnya, memilih sumber yang cocok dan reliabel) dan waktu untuk membaca, mempelajari, dan melakukan adaptasi konten sejarah untuk digunakan dengan siswa. Alasan tersebut didukung oleh keterbatasan waktu untuk mengajarkan karena sejarah matematika dipandang sebagai tambahan dalam kurikulum matematika.

\section{Simpulan}

Penerapan sejarah matematika dalam pembelajaran memberikan banyak kontribusi positif, yaitu: (a) memunculkan antusias (Fauvel, 2000); (b) sebagai sumber contoh yang menarik dan menyenangkan dalam pembelajaran serta membuat siswa memahami bahwa matematika bukan pelajaran tanpa makna (Bruckler, 2001); (c) meningkatkan motivasi dan minat siswa; matematika sebagai capaian manusia sehingga siswa tidak dilemahkan oleh kegagalan, kesalahan, ketidaktentuan, dan 
kesalahpahaman (Tzanakis \& Arcavi, 2000). Ketiga hal tersebut bisa memberikan kontribusi positif dalam mengubah pandangan (Schoenfeld dalam Riedesel, dkk. 1996) dan sikap siswa terhadap matematika yang diawali dengan adanya antusias dalam belajar (Fauvel, 2000), peningkatan motivasi dan minat (Lawrence, 2008; Tzanakis \& Arcavi, 2000), merasa senang dalam pembelajaran (Bruckler, 2001) dan percaya bahwa matematika adalah capaian manusia yang dilalui dengan kerja keras (Tzanakis \& Arcavi, 2000).

Dalam konteks pembelaran matematika di Indonesia, capaian aspek afektif dan kognitif dalam pembelajaran matematika menjadi dua hal penting yang harus diperhatikan dalam menerapkan sejarah matematika. Berdasarkan hasil analisis penerapan sejarah matematika oleh Jankvist (2009b), Furingheti (1997), Siu (1997) serta Tzanakis dan Arcavi (2000), pendekatan berdasarkan sejarah (history-based approach) lebih menjanjikan untuk diterapkan dalam pembelajaran matematika. Guru matematika dapat mengembangkan materi didaktik sejarah matematika yang diolah dari sumber primer dan/atau sumber sekunder. Materi didaktik ini berupa anekdot, konteks pembelajaran sejarah untuk topik atau konsep yang akan diajarkan, dan latihan. Ketiga materi didaktik ini disusun dalam bentuk lembar kerja (LK) untuk kelompok atau individu. Materi didaktik yang sangat penting ada dalam LK adalah konteks pembelajaran berdasarkan konten sejarah untuk membangun dan mengembangkan ide atau konsep matematika siswa.

\section{Daftar Pustaka}

Barbin, E. (2000). Integrating history: Research perspective. In J. Fauvel, \& J. van Maanen (Eds.), History in mathematics education (pp. 63-90). The ICMI Study. Dordrecht: Kluwer Academic Publishers.

Bruckler, F.M. (2001). Using history for popularization of mathematics. Diakses di https://web.math.pmf.unizg.hr/ bruckler/trondheim small.ppt Clark, K.M. (2011). Voices from the field: incorporating history of mathematics in teaching. Proceedings of the Seventh Congress of the European Society for Research in Mathematics Education ( $7^{\text {th }}$ CERME), Rzeszow - Poland, 1640-1649.

Fauvel, J., \& Maanen, J.v. (Eds.). (2000). History in mathematics education: The ICMI study. Dordrecht, Netherland: Kluwer Academic Publishers. 
Fauvel, J. (2000). The role of history of mathematics within a university mathematics curriculum for the $21^{\text {st }}$ century (Artikel web). Diakses di http://www.bham.ac.uk/ctimath/talum/newsletter

Goodwin, D.M. (2010). The importance of mathematics teachers knowing their mathematics history. The Journal for Liberal Art and Science, 14/2, 86-90. Diakses di http://www.oak.edu/academics/school-arts-sciencesjlas-archive.php\#Fa2010

History of Mathematics. (t.t). dalam Wikipedia. Diakses di https://en.wikipedia.org/wiki/History of Mathematics

Hughes, B. (2011, Agustus). Completing the Square- Quadratic using addition (Artikel web). Diakses di http://www.maa.org/press/periodicals/convergence/completing-thesquare-quadratics-using-addition

Kjeldsen, T.H. (2011). Uses of history in mathematics education: Development of learning strategies and historical awareness. Proceedings of the Seventh Congress of the European Society for Research in Mathematics Education (7th CERME), Rzeszow - Poland, 1680-1689.

Jankvist, U.Th. (2009a). Using history as a goal in mathematics education (Master thesis). Diakses di http://milne.ruc.dk/imfufatekster/pdf/464.pdf Jankvist, U.Th. (2009b). A categorization of the 'whys' and 'hows' of using history in mathematics education. Educational Studies in Mathematics, 71/3, 235-261. Doi:10.1007/s10649-008-9174-9

Lawrence, S. (2005). Maths is good for you: Teaching mathematics in a historical context (Artikel web). Diakses di http://www.mathsisgoodforyou.com/

Lawrence, S. (2008). History of mathematics making its way through the teacher networks: professional learning environment and the history of mathematics in mathematics curriculum. Paper presented at $10^{\text {th }} \mathrm{ICME}$, Mexico.

Marks, J.L., Hiatt, A.A. \& Neufeld, E.M. (1985). Metode mengajar matematika untuk sekolah dasar (Terjemahan oleh Bambang Sumantri). Jakarta, Indonesia: Penerbit Erlangga.

Muhammad ibn Musa al-Khwarizmi. (t.t). dalam Wikipedia. Diakses di https://en.wikipedia.org/wiki/Muhammad ibn Musa al-Khwarizmi

O'Connor, J.J. \& Robertson, E.F. (1999, Juli). Abu Ja'far Muhammad ibn Musa Al-Khwarizmi (Artikel web). Diaskes di http://www-history.mcs.stand.ac.uk/history/Biographies/Al-Khwarizmi.html

Panasuk, R.M \& Horton, L.B. (2012). Integrating history of mathematics into curriculum: what are the chances and constraints? IEJME, 7/1, 3-20. Diakses di http://www.iejme.com/makale/284

Riedesel, C.A., Schwartz, J.E. \& Clements, D.H. (1996). Teaching elementary school mathematics. Boston, USA: Allyn \& Bacon. 
Sembiring, R.K., Hadi, S., \& Dolk, M. (2008). Reforming mathematics learning in Indonesian classroom through RME. ZDM: The international journal on mathematics education, 40(6), 927-939. doi: 10.1007/s11858-008-0125-9

Siu, M.K. (1997). The $A B C D$ of using history of mathematics in the (undergraduate) classroom. Bulletin of the Hong Kong Mathematical Society, 1/1, 143-154. Diakses di http://hkumath.hku.hk/ mks/ABCD.pdf

Sumardyono. (2003). Sejarah topik matematika sekolah. Diakses di http://p4tkmatematika.org/2012/08/pemanfaatan-sejarah-matematikadi-sekolah/

Tzanakis, C., \& Arcavi, A. (2000). Integrating history of mathematics in the classroom: An analytic survey. In J. Fauvel, \& J. van Maanen (Eds.), History in mathematics education (pp. 201-240). The ICMI Study. Dordrecht: Kluwer Academic Publishers.

Wahyu, K. (2015, November). Changing mathematics classroom setting: looking into students' response and performance in learning. Paper presented at International Conference on Mathematics, Science and Education Mataram University, Mataram - Indonesia. 